\section{Down syndrome and quality of life: some challenges for future practice}

\section{Roy I Brown}

\author{
Professor, Rehabilitation Studies \\ The University of Calgary \\ Alberta, Canada
}

This article examines the perceptions and performance of a group of people with Down syndrome. This quality of life research is based on a six year study and compares the individuals' performance with others with developmental disabilities. Twenty-seven people with Down syndrome ranging in age from 18-43 took part in the project and received individually chosen intervention for the last three years of the study.

Over the six years, their Verbal IQ increased significantly. They also made significant gains in applying reading, writing and numerical skills in social contexts. Surprisingly, social behaviour and performance in a work setting declined after community training according to the rating of service providers, suggesting that training leads to gains in behaviour which are useful in the community, but less valued in traditional agency services. Individuals tended to be more dissatisfied after intervention as they became more aware of their needs and therefore more critical of their environment.

\section{Acknowledgement}

The author wishes to thank the people with Down's syndrome and the sponsors who took part in the study.

(C) 1993, 1999. The Down Syndrome Educational Trust Down Syndrome Research and Practice 1994, 2 (1) 19-30
Introduction

In recent publications Brown, Bayer and MacFarlane (1989) and Brown, Bayer and Brown (1992) described the performance and quality of life of 240 adults who were classified as developmentally delayed. In brief, the authors noted that as a general rule the individuals had clear impressions of their lifestyle, and had major concerns over aspects of their progress. Sponsors, generally parents, had similar views but there were important differences, particularly in the area of emotional needs and assertiveness.

The authors, in the last three years of the six year study, carried out specialised interventions (referred to as the intervention group) based on choice of the individuals over activity, place of intervention and selection of intervenor. In those clients who received intervention considerable progress was made in aspects of performance such as social skill development, but probably the greatest differences were observed in the positive changes in self perception, in the understanding of needs and a recognition of the relevance of emotional support. Such changes were shown to be greater than in previous periods in the study when such personal intervention did not occur, and were also greater than in those clients who continued with normal agency programmes. In brief, one on one personal intervention based on choice of activity and environment (activities generally taking place in the client's home or local community) resulted in improvement, not only performance on selected intervention activities, but in other areas of performance where no known intervention took place. In other words this type of intervention appeared to have major transfer effects. The study then, was about empowerment, choices and learning which the authors identified as important aspects of any quality of life model.

The present paper looks at a group of people, involved in the above study, who had Down syndrome. There are a number of reasons why it might be useful to examine such a subgroup. Gibson (1978) has suggested that there are a number of features amongst people with Down syndrome which are different from other persons who are developmentally delayed. Selikowitz (1992) also provides medical and behavioural details which illustrate some of the vulnerabilities, life span changes and community behaviour of persons with Down syndrome, which further support the idea of looking at such a group separately. The change in longevity of people with Down syndrome from around nine years at the turn of the century to over 50 years at present, with one in 10 living to 70 years or more, makes the issues of quality of life critical in the understanding, and rehabilitation of such individuals. For example, as pointed out elsewhere (Pueschel, 1988 and Brown, 1993), the changes in life span opens up a myriad of challenges in relation to work, community and home living, which involve the development of relationships, freedom to explore, and learning to be an active participant in all aspects of life.

\section{Quality of life}

The definition of quality of life in this study is the difference between a person's achieved and unmet needs and desires regardless of baseline (see Brown et al. 1989). Such a definition applies holistically, and includes employment or work, home living, community, educational, social and leisure and recreation needs. Indeed, quality of life studies in the field of developmental disabilities indicate that such a conceptualisation is crucial to an understanding of the 
individual. However, quality of life also critically sees the individual in the context of his or her environment. Knowledge of an individual's quality of life comes about through the use of both objective and subjective techniques. The perceptions of the individual over time are important and are linked to having choices and control over the environment.

\section{Assessment techniques}

In order to measure some of these attributes Brown and Bayer (1993) developed a quality of life questionnaire which was given to each individual, and separately, to the individual's sponsor, on three occasions designated as years one, three, and six in the study. Correlational studies indicate that such measures are very reliable - people with disabilities are capable of giving consistent responses much to the surprise of some clinicians. The questionnaire has twelve sections of which five, relating to social, emotional and home activities, have been selected as they have proved particularly sensitive in the previous studies referred to earlier.

It will be recalled that for some clients individual quality of life interventions took place between years three and six. The following account describes the results obtained and, where appropriate, contrasts them with data obtained from the tota developmentally disabled group (see Brown, Bayer and Brown, 1993, for precise data). The total group was selected for comparison as details of this group have previously been published (see also Brown et al. 1989).

In addition to the above questionnaire an abbreviated WAIS test was employed. The objective Social Education Adaptive Functioning Index (AFI) (Marlett, 1976), which measures a range of reading, writing and numerical skills and their application in social contexts, was also given along with the Vocational AFI which is a rating scale measuring individuals' social and performance behaviour in work situations.

\section{Sample}

The sample consisted of 27 people with Down syndrome. It should be noted that responses were not obtained on all variables, either from the clients or the sponsors, therefore sample size varies from one data unit to another. Details of people's age and gender at year one of the study are given below.

At year one the mean age was 25 years for males (range 20-30 years of age) and 29 years for females (range 18-45 years of age). There were 13 males and 14 females. On average the females were approximately four years older than the males though the difference was not significant.

\section{Results}

The results are described for the total group and also for intervention and non-intervention sub-groups. Because specialised intervention only took place during the last three years of the study, years one and three represent some indication of the stability of the data while individuals attended rehabilitation agencies full time. Where appropriate gender differences are recorded.

\section{Intelligence test results}

Intelligence test levels on the WAIS showed equivalent Verbal and Performance scores which were in the low fifties. There was no significant difference between males and females. The only difference in scores from year one to year six was a small increase in Verbal IQ for the group with Down syndrome as a whole, which reached significance at $\mathrm{P}<$ 0.05 (1 tail). Some increase might be expected due to regression effects. There appear no differential changes between intervention and non-intervention subjects unlike the total developmental disability group. Overall, the group with Down syndrome were about 5-8 points lower than the total disability group. However, the much lower sample size of the former must be kept in mind.

\section{Social Education AFI}

In the results on the Social Education Adaptive Functioning Index the total group of clients with Down syndrome showed significant increases, though there was no differential effect between the intervention and non-intervention groups between years three and six. Indeed in terms of the total scores on the AFI the mean increase was 4.3 and 5.6 respectively. The pattern of scores amongst the sub-tests indicates no differential effects between intervention and non-intervention groups unlike the findings in the Brown et al. (1992) developmental disability group, where intervention effects were clearly shown. The average scores of the group with Down syndrome at year one was 55 on the Social Education AFI - 19 points below that of the total disability group.

The females score numerically higher at initial assessment on seven of the nine Social Education subscores. Concept attainment and money skills were the only areas where males scored slightly higher numerically. Females were markedly higher in reading, writing and number skills. Overall this difference does not reach acceptable levels of significance though appears reliable as it is repeated at the other assessment years.

\section{Vocational AFI}

The Vocational AFI total scores of the group with Down syndrome are very similar to those of the total developmental disability group. The mean scores are 74 and 80 for the clients with Down syndrome and 71 and 76 for the total disability group at years one and three. The subtests of basic work habits, work skills and acceptance skills follow a similar pattern. The non-intervention group with Down syndrome remained the same during years three to six while the intervention group showed a change over this period, dropping from a mean of 83 to 66 . These results although not statistically significant are similar in direction to the total developmental disability group in terms of intervention and non-intervention effects where significance was found. The conclusion drawn from the major study was that, although agency personnel rated people as lower after intervention, this probably was a measure of non-conformance by clients or a lack of knowledge by the raters, since individuals were now spending much more time outside the agency, and some had left and obtained work. This raises the question whether more wide ranging community training results in behaviour which is less acceptable within traditional agencies and much more useful in the community!

\section{Quality of Life Questionnaire}

The performance on the quality of life measures as seen by the clients can be observed from Figure 1. In year one 11 and 12 items in the two groups respectively (intervention and non-intervention) fell below 50 per cent and these are the same items. Most of the low scoring items represent basic domestic activity. Buying groceries and meal preparation can be seen to be particularly low, and this is true of 
Figure 1. Quality of Life Questionnaire - Question 10 from Residential Section

1A. Intervention group - client questionnaire $(n=9)$

Percentage who are 'satisfactory without supervision'

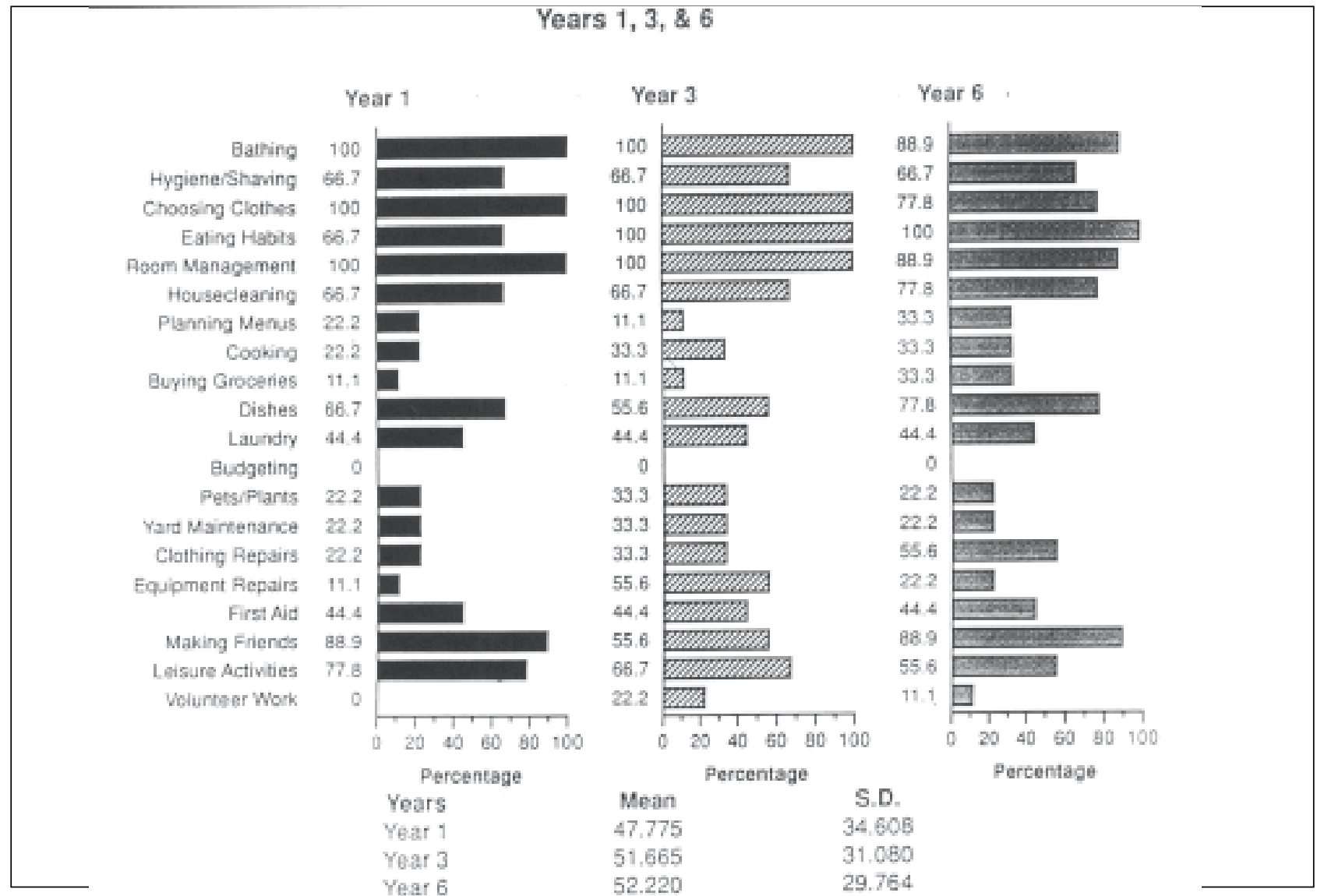

1B. Non-intervention group - client questionnaire $(n=18)$

Percentage who are 'satisfactory without supervision'

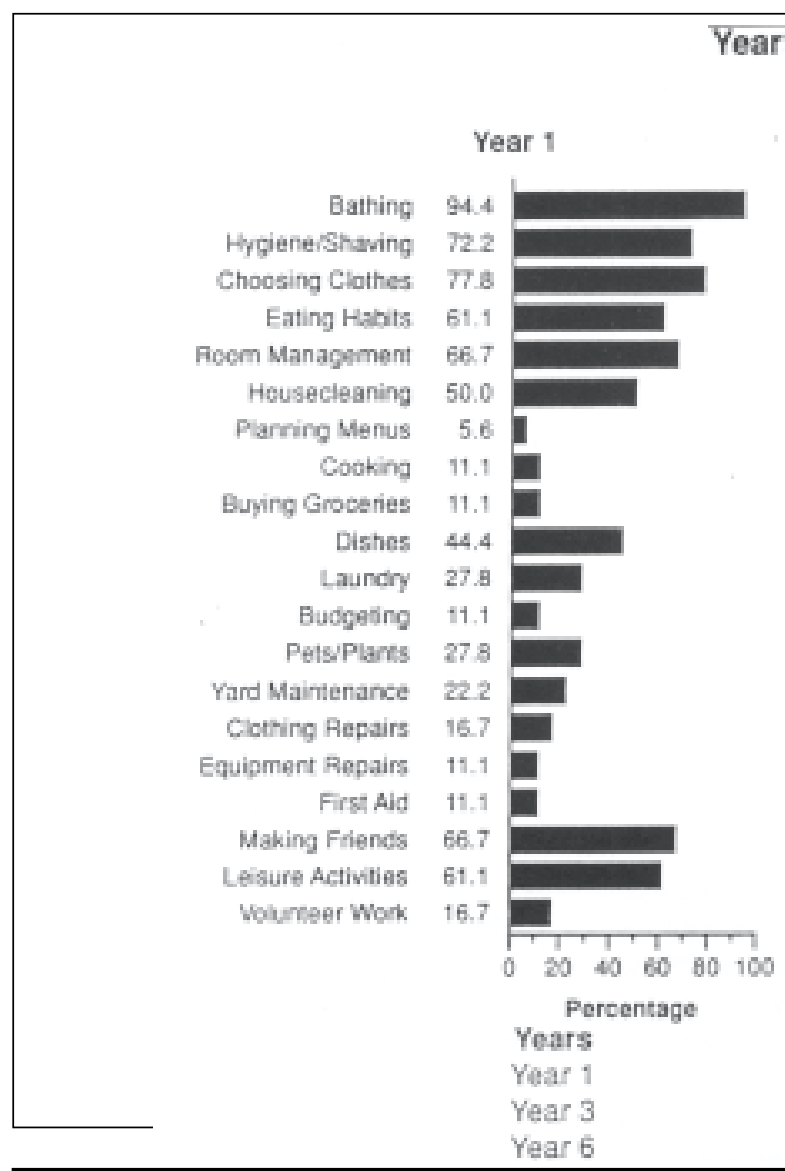

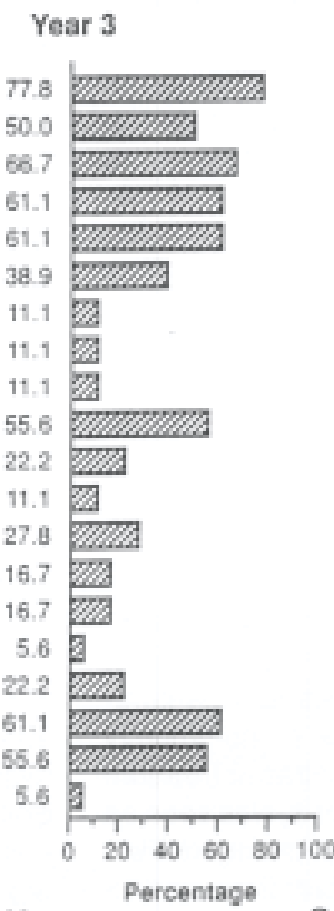

Mean

38.335

34.455

40.000
Year 6 .

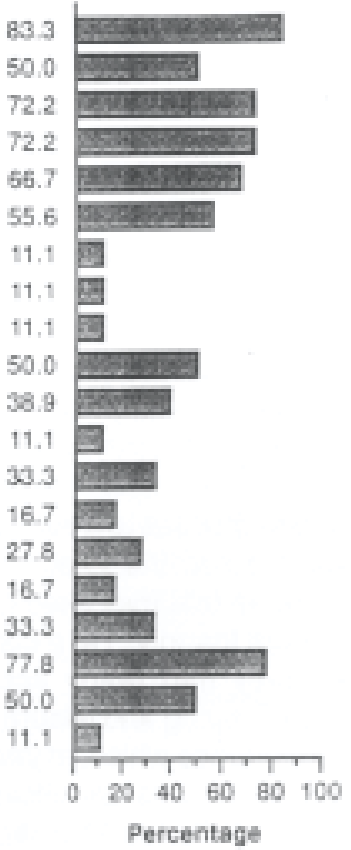

S.D.

27.971

24.090

25.273 
1C. Non-intervention group - sponsor questionnaire $(n=12)$

Percentage who are 'satisfactory without supervision'

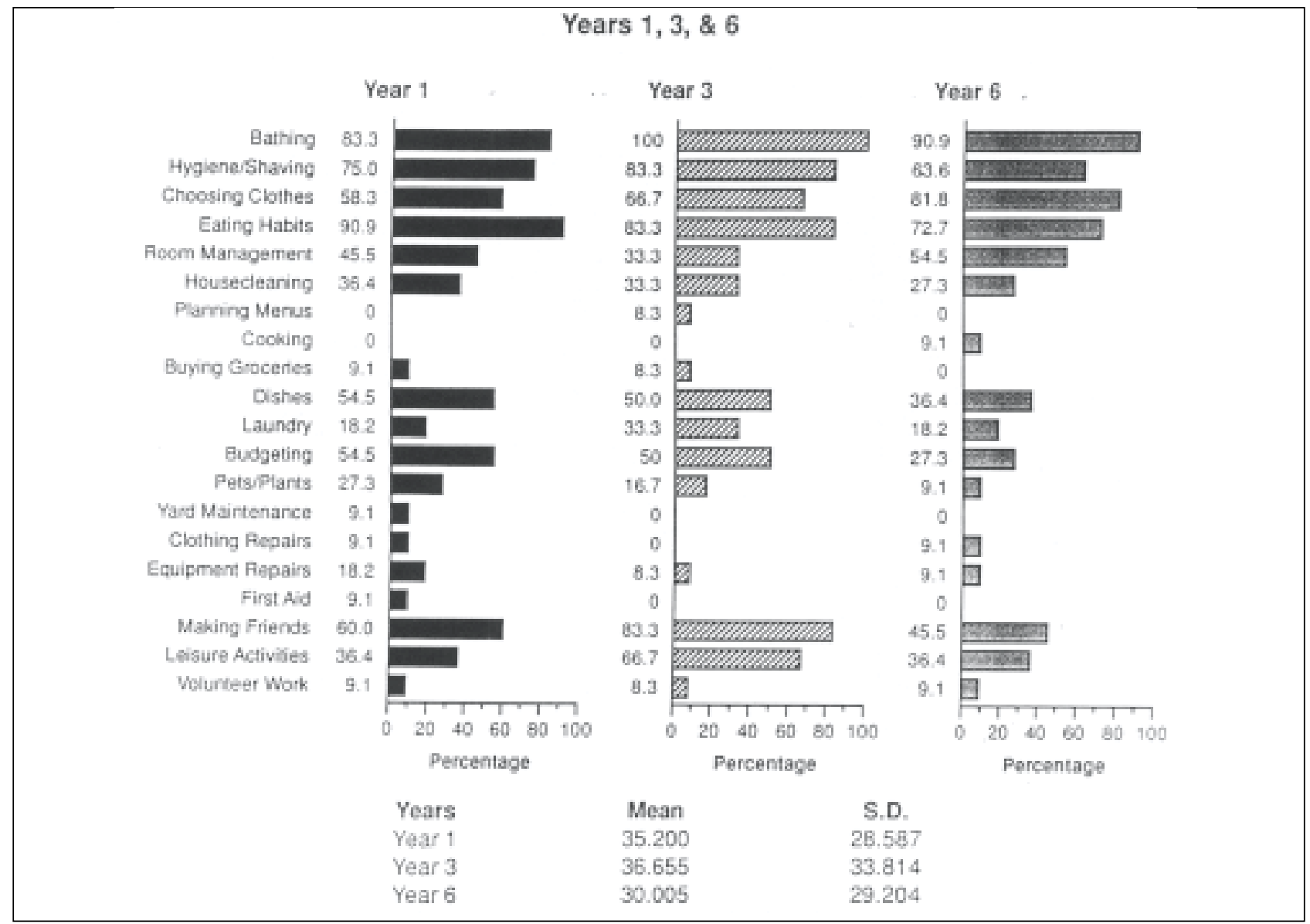

(The statistical analyses in the text relating to the figures are based on the number of categories not the number of clients.)

budgeting and all types of home maintenance. In other words activities which are other than simple or routine and probably activities which would directly affect other family members do not feature as activities carried out by most people with Down syndrome. The same pattern is preserved by both groups over the six years of the study with a significant rise between years three and six in the nonintervention group. $(t=3.5$, df $19, p<0.002)$ yet this is balanced by a significant drop from year one to three in the same group. Comparison with the total group of people with developmental disabilities suggests there is considerable similarity, except in the budgeting and equipment repair items which are perceived to be much lower in the Down group. A similar pattern of results was obtained from sponsors' reports, suggesting considerable reliability of perception between the clients and the sponsors.

Figure 2 shows the responses to a series of questions about the clients' residence and the relation to the community. Most individuals stated that they liked their neighbourhood and found neighbours friendly. Yet a considerable percentage did not see they had ready access to community resources such as shopping and leisure centres or freedom to move from the residence which, at year one, was seen as very restricted. Both groups significantly changed their perceptions over the years, and between years three and six there was change at or beyond the $p<0.001$ level in both the intervention and non intervention groups. However in the main study there was a significant decrease in the intervention group which was perceived as increased dissatisfaction with living conditions, i.e., individuals became more aware of their needs therefore more critical of their environment.

Figure 3 (on pages 24,25) examines the types of assistance perceived as necessary. Over the six years there was a dramatic increase in the levels of need perceived as necessary, and this increase was particular great between years one and six. Three of the highest perceived needs were, by year six, emotional support, assertiveness training and help with budgeting skills. It will be noted that assistance in finding a job did increase over the years in the non-intervention group, but did not reach the level for the other characteristics. The overall pattern is not dissimilar to the full study sample. It seems important that needs were seen initially as unimportant. The question is whether the growing perception of need over the years was responded to by sponsors and professionals. An examination of sponsor responses shows virtually no change over the years, but the clients came to see the needs similarly to the sponsors by the sixth year of the study. This is important because agreement in perception is likely lead to more joint and appropriate action. The question is, given the age of the clients, what methods might more rapidly bring about their awareness of need. Sponsors, like clients, perceived assertiveness training as necessary $(75$ percent of both samples), and 42 per cent registered emotional support as important. Budgeting, shopping and meal preparation were also seen as critical needs. Clients in the intervention group and sponsors saw the meeting of spiritual needs of the clients as an important issue over the six years of the study. 
Figure 2. Quality of Life Questionnaire - Question 7 from Residential Section

$2 A \quad$ Intervention group - client questionnaire $(n=9)$ "How do you feel about your residence"

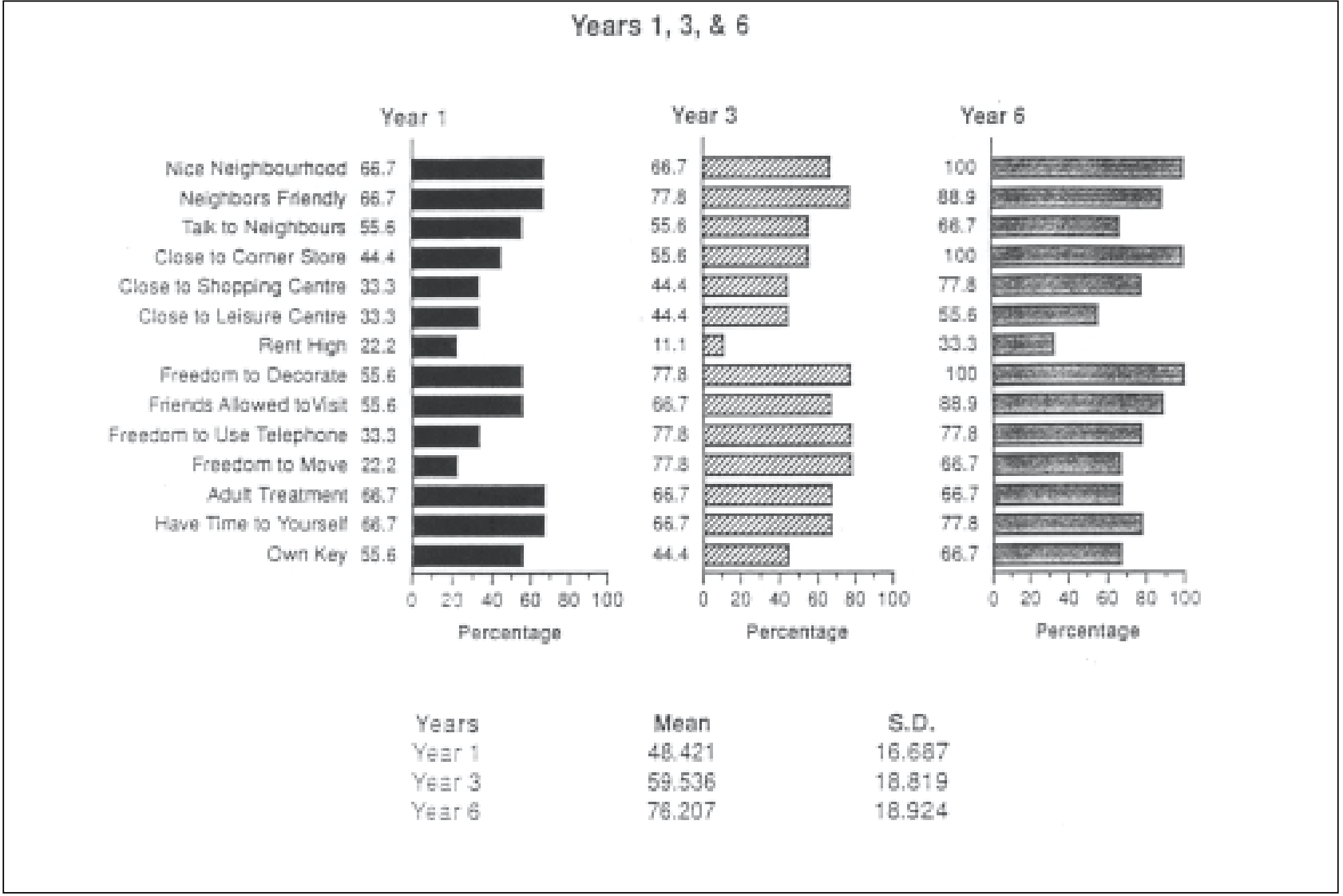

2B. Non-intervention group - client questionnaire $(n=$

18)

"How do you feel about your residence"

Years $1,3, \& 6$

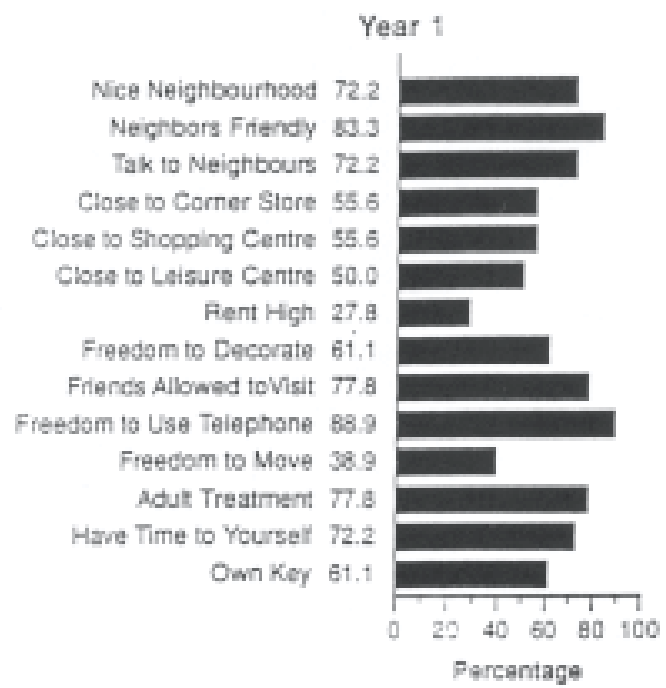

Years

Year 1

Year 3

Year 6
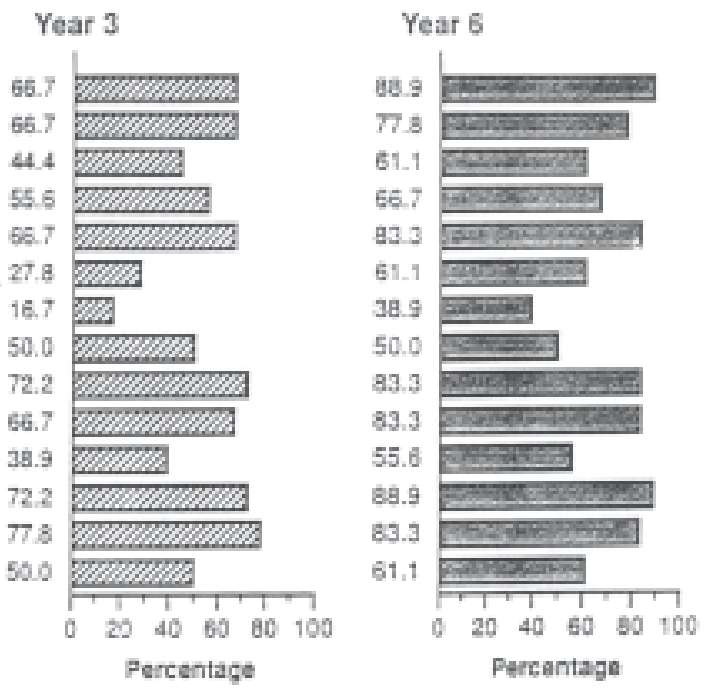
Figure 3. Quality of Life Questionnaire - Question 1 from General Section

3A. Intervention group - client questionnaire $(n=9)$

"Types of assistance needed now"

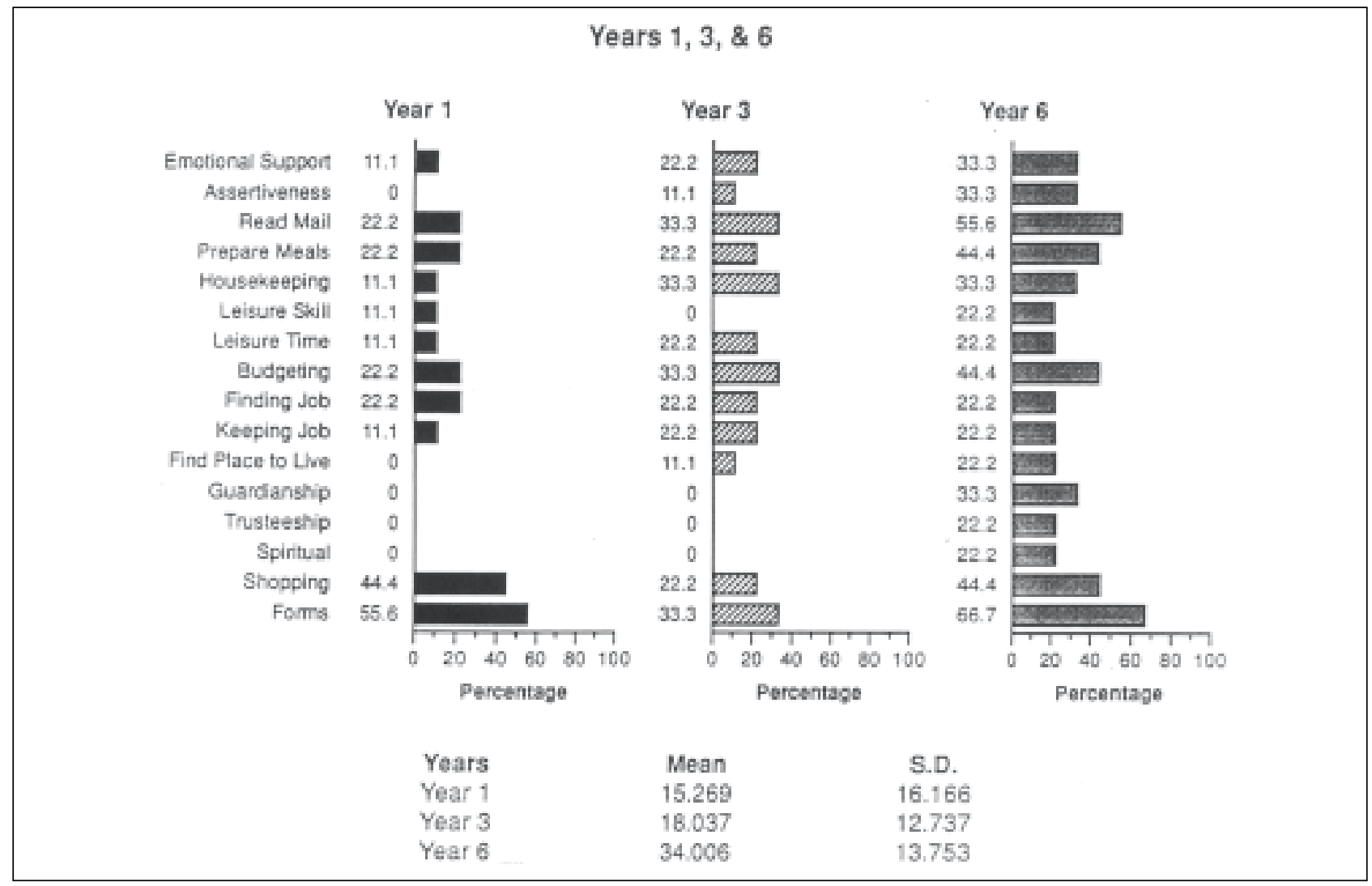

3B. Non-intervention group - client questionnaire $(n=$ 18)

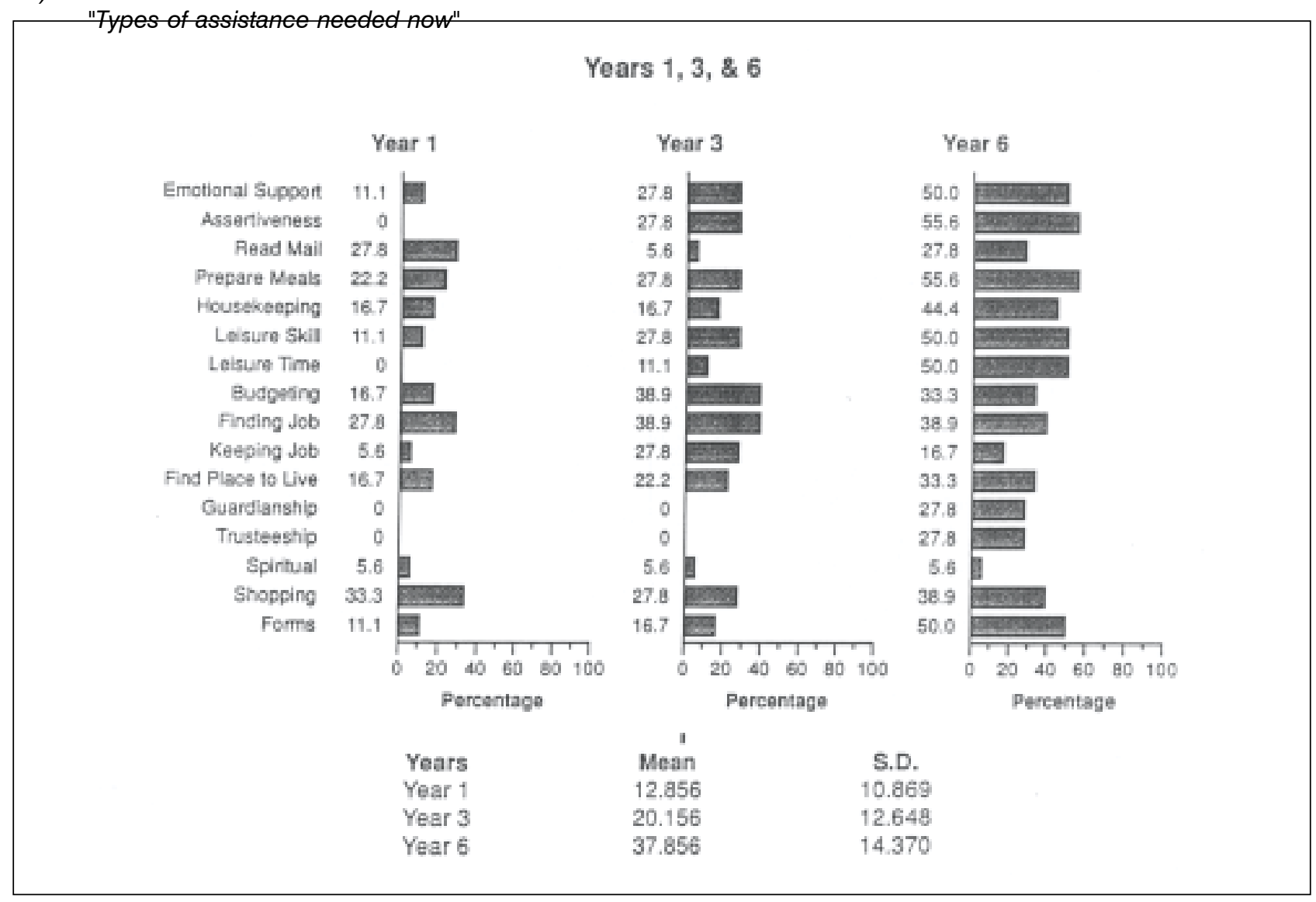


3C. Non-intervention group - sponsor questionnaire $(n=12)$ "Types of assistance needed now"

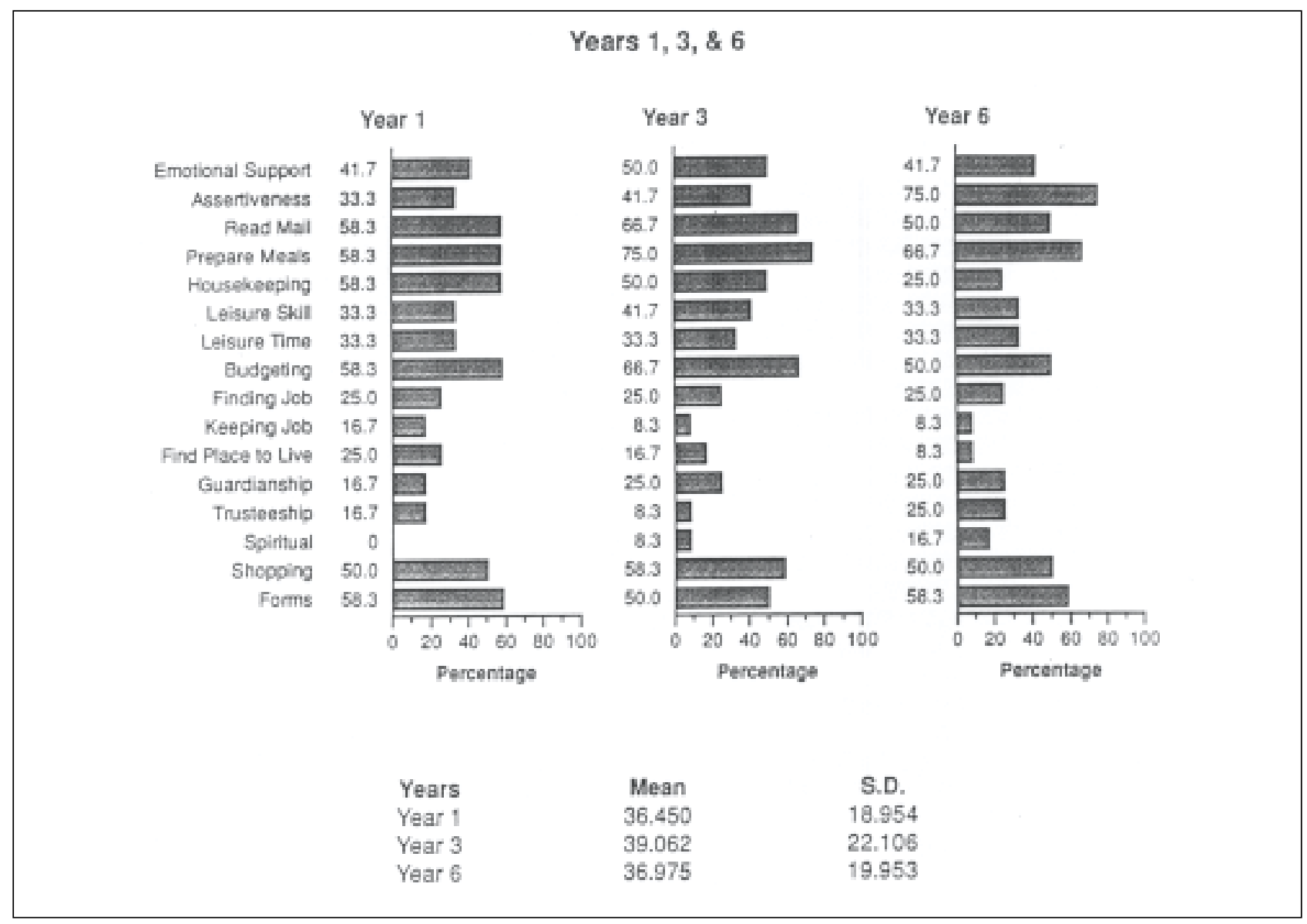

The next figure (Fig. 4 on pages $26,27,28$ ) shows activity in leisure and recreation areas. The overall patterns of activity were fairly similar, but greater amongst the intervention group. Over the years there is a decline in terms of the numerical listing of involvement, but this does not quite reach significance. However the only group to show an increase in scores was the intervention group in the main study. It is of interest to note that in the group with Down syndrome drinking coffee, going out for dinner, watching TV, listening to records playing, games and going shopping were carried out the most frequently. Going bowling and attending the movies were also seen as popular amongst the intervention group. Dancing, exercise and playing catch were also higher in the intervention group. In other words although the range of activities were quite similar, and low activity leisure involvement was the most popular, more energetic activities featured in the responses of the intervention group. On the other hand sponsors saw a decline in activities over the six years $(t=3.10$, df $28, p<0.005)$.

Figure 5 (on page 29) shows the perception of clients around areas of improvement. The non-intervention group significantly declined over the six years $(t=3.2$, df $17, p<0.005)$ whereas the intervention group did not change. This is in direct contra-distinction to the total disability group where the intervention group made significant improvement and the non-intervention group showed no change. Indeed, whereas the majority of clients showed improvement in most categories in the intervention group of the study the nonintervention group with Down syndrome showed no category above $50 \%$ in year six, and had the lowest mean score in the whole study. For the intervention group with Down syndrome reading, writing, getting around the community and cooking meals were seen to have improved and, along with some other items were responded to at or above the 50 per cent level. It will be noted that these included some of the items over which sponsors noted concerns earlier in the study.

\section{Discussion}

The results must be interpreted with some caution for the number of clients in the group with Down syndrome is small, particularly in relation to the total disability group described in Brown et al. (1989 \& 1992). However, there are some interesting indicators. Not unexpectedly the group with Down syndrome tended to function at a lower level than the total disability group, though this is not true of vocational skills in training centres where their performance is remarkably similar. The group with Down syndrome are of slightly lower intelligence and their average Social Educational AFI results are 19 points lower.

The females were slightly older than the males and tended to have higher scores at each assessment year. Although these results were not individually significant their repetition on three separate occasions cannot be ignored. There was a suggestion in the full study on developmental disabilities that females outperformed males in social education and positive change in self image during intervention. The question is why this should be. The most likely possibility is that females are not permitted to take as many risks as males, are more protected in various activities and are more likely to 
Figure 4. Quality of Life Questionnaire - Question 1 from Leisure Section

4A. Intervention group - client questionnaire $(n=9)$

Percentage who participated in leisure activities "often" and "sometimes" combined.

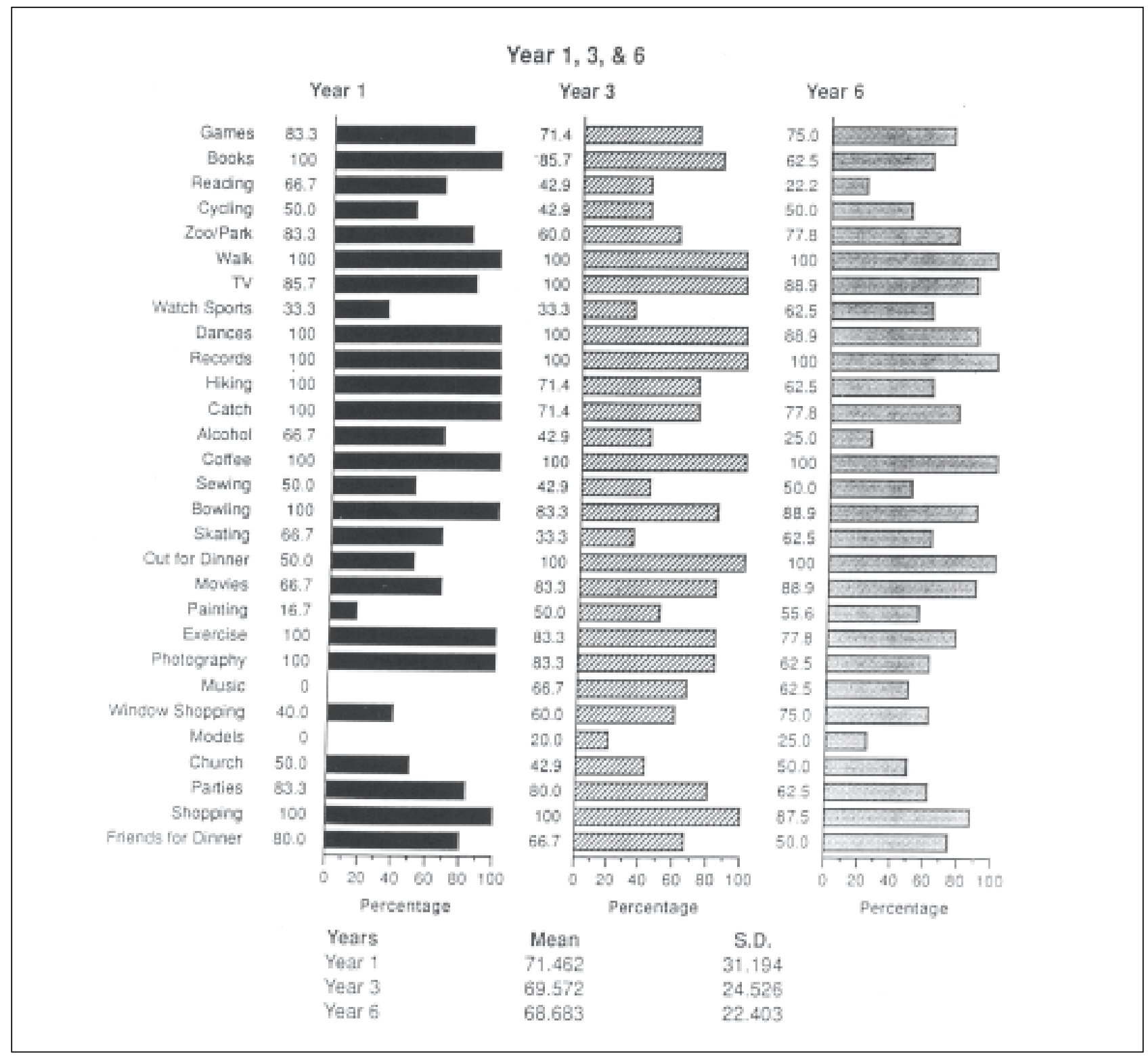

remain in training agencies. Once intervention involving choice and individual support occurs they are seen to make more improvement in certain areas. The present results support this notion in that females have higher numerical scores on most variables.

Some improvements over the six year period were observed and these favoured in a few cases the intervention group. However, as a rule the group with Down syndrome tended to maintain their scores or show slight improvement, but in the non-intervention condition they remained the same or at times deteriorated. This is particularly marked in the selfimage area. It is of interest that spectator and low activity interests tended to predominate though, once again, there was some indication of greater perceived interest in a wider range of activities in the intervention group with Down syndrome. The results tend to suggest slow growth, some deterioration, poor self image, and concerns over the range of leisure interests, with intervention tending to stabilise or even improve perceived performance. However, the positive changes, where they occurred, were less marked than in the total disability group. This statement may be an underestimate, because the group with Down syndrome formed part of the total disability group thus masking the performance of the rest of the subjects. The discrepancy may be greater.

The group with Down syndrome is also associated with a much higher no response rate than the total group. In fact it is approximately three times greater, and this is particularly associated with years one and three of the study suggesting this lessened either with age or because of intervention.

Although several reasons might be considered for these various results one possibility is of major concern. Low response rates may be associated with poor motivation. 
4B. Non-intervention group - client questionnaire $(n=18)$.

Percentage who participated in leisure activities "often" and "sometimes" combined.

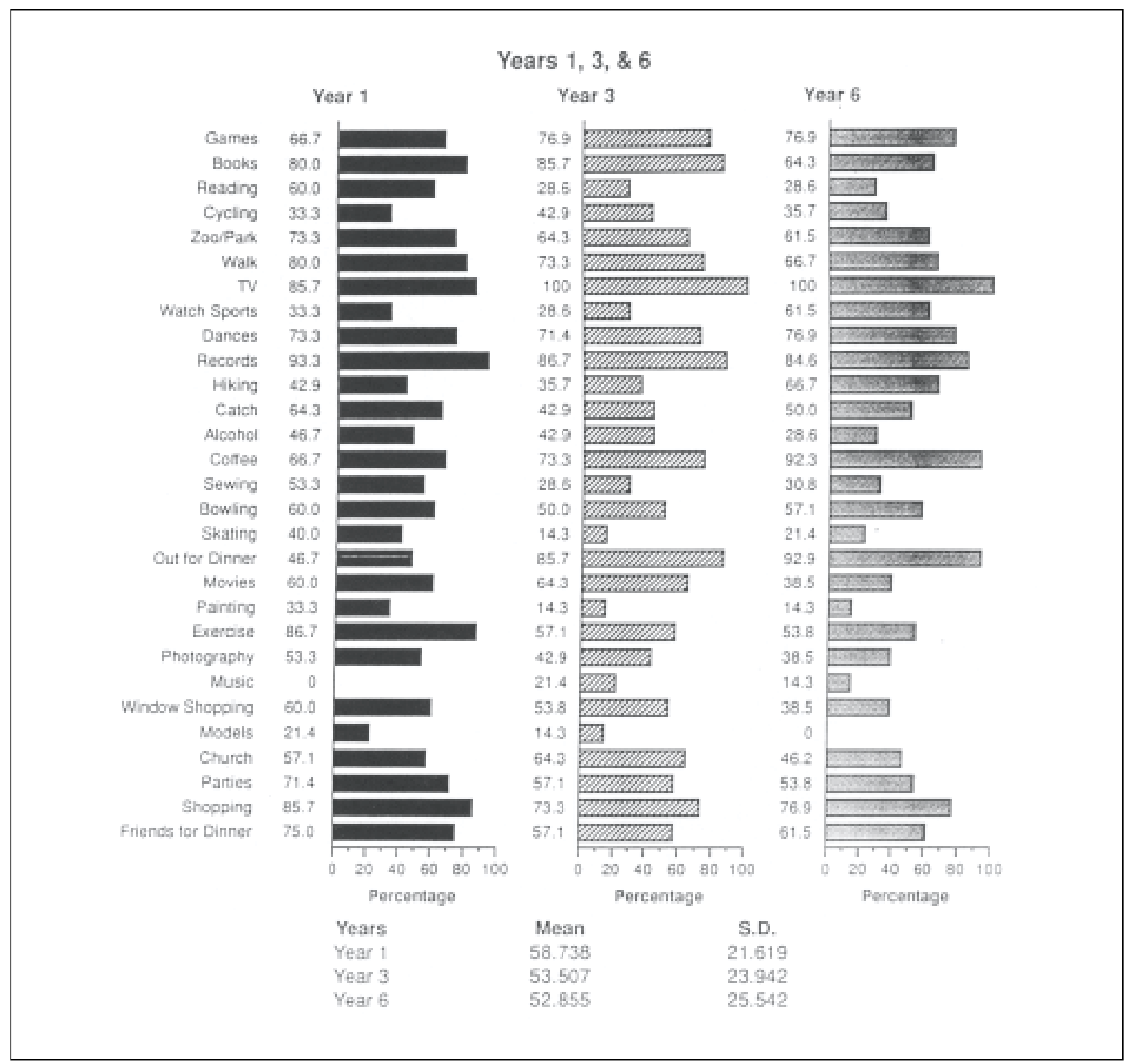

Other reports have noted allied behaviour favouring low activity possibly associated with problems commonly associated with Down syndrome (e.g. obesity, heart defects, hypo-thyroidism), and this is not inconsistent with early ageing and lower life expectancy (see Gibson, 1978, Pueschel, 1988).

The fact that those clients and their sponsors, who offered themselves for intervention, tended in the first place to score more highly than their non-intervention peers may suggest that a higher level of performance, or perhaps a sponsor's view about the possibility of improvement may be relevant to gaining intervention in the first place (see Brown et al., 1992). This appears to represent a self-fulfilling prophecy and is not inconsistent with the results on self image, low response rates and, possibly, poor motivation. If such an interpretation is correct the current situation for some people with Down syndrome must be even more limited than sug- gested by the present results. Parents, in particular, need to be persuaded of the importance of specific approaches to intervention even when the individual is unconcerned. Where they are interested and lean to particular choices these should be respected, even though they may not be the selection of the parent or professional. The views on emotional support and the need for assertiveness training both by sponsors and clients provide some indicators. This view is even more interesting because it would appear that many parents see the need for such assistance, but are unable to provide it. Clinical experience suggests that this may be due to a reluctance to take risks or a reluctance to encourage behaviour which may lead to differing opinions or actions within a family. After all, if the person with Down syndrome is in their twenties or thirties parents are probably seeking or wanting a less confrontative family life! It is in this context that individualised intervention based on choices and specifically directed to expressed needs seem to be relevant 
4C. $\quad$ Non-intervention group - parent/sponsor questionnaire $(n=12)$.

Percentage who participated in leisure activities "often" and "sometimes" combined.

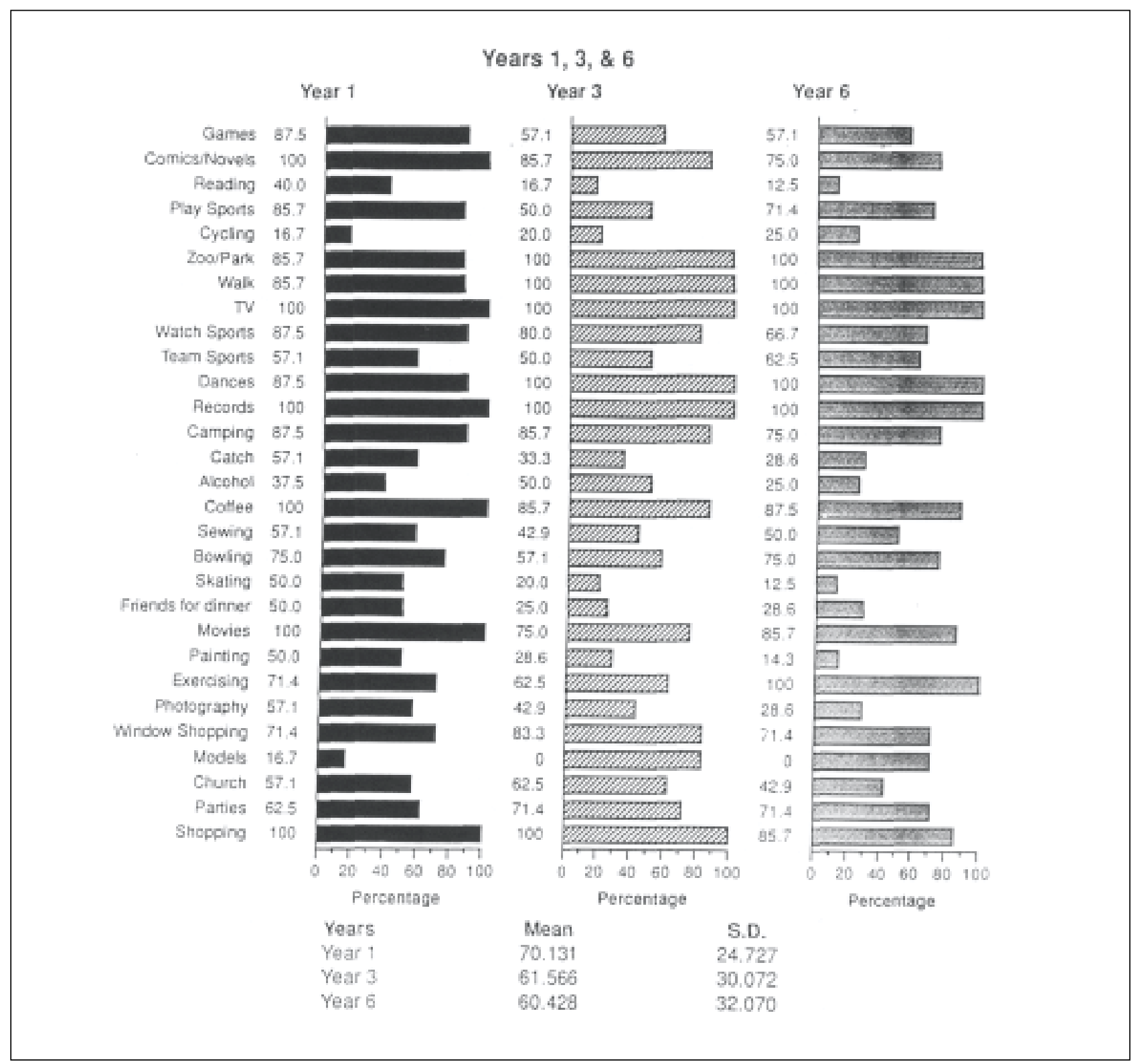

(See Brown, Bayer and Brown, 1992, and Lawrence et al. 1993 for details). The fact that there is some evidence that change in perception may positively occur under such conditions, and the views of client and sponsor may come to more closely match each other, can also be relevant in making intervention more potentially effective.

\section{Conclusions}

As persons with Down syndrome are living longer it becomes even more important to consider the relevance of quality of life issues. The present results suggest that gains in this area are not what they might be, and that during the thirties individuals are likely to stagnate or show minimal growth. Where growth occurs changes in the individual's perception are important, and more optimistic perceptions need to be encouraged. There is some evidence that individualised interventions directed to choice and empowerment may have an important role to play as they have with the broad range of people with developmental disabilities. Such interventions, based on the individual's choice, are likely to occur in the areas identified above (community skills, emotional and assertiveness needs). Community supports, access and activity are noted, along with more active leisure pursuits. These are all particularly important as the life span of persons with Down syndrome increases. The social, community and leisure issues may play a further role in extending life span. It is recommended that further studies of this type are undertaken with people who have Down syndrome to explore these aspects in greater depth. In the meantime, the need to encourage positive motivation in parents as well as clients is important. Change can take place in adult life, but traditional expectations may hinder this. 
Figure 5. Quality of Life Questionnaire - Question 1 from Self Image Section

5A. Intervention group - client questionnaire $(n=9)$.

"Perception of skill improvement".

Years 1, 3, \& 6

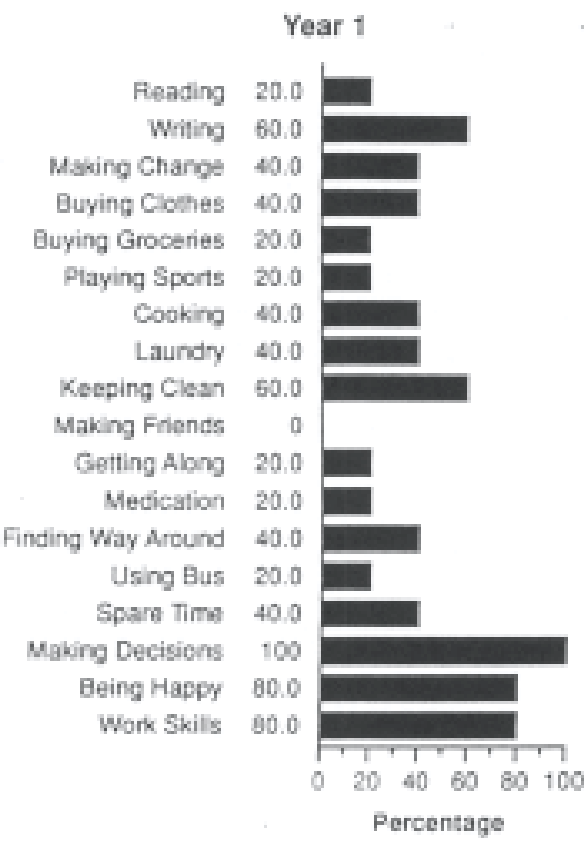

\section{Year 3}

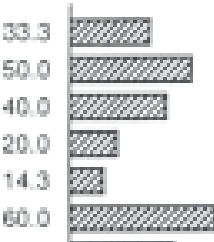

429 WIIIITA

$14.3 \mathbb{Z}$

60.0 WIIIIIIIIA

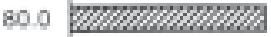

80.0 TIIITIIIIIII

40.0 WIIIZZ

0

60.0 TIIIIIII

60.0 WIIWH

40.0 WIIIII/

80.0 VIIIIIUIIIIZ

60.0 WIWHIIIVA

$0 \quad 20 \quad 40 \quad 60 \quad 80 \quad 100$

Percentage

Mean

41.111

46.378

41.706
Year 6

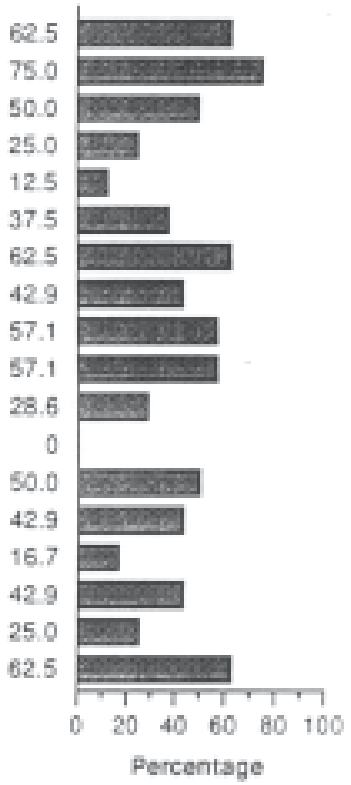

S.D.

26.097

23.692

20.273

5B. Non-intervention group - client questionnaire $(n=18)$.

"Perception of skill improvement".

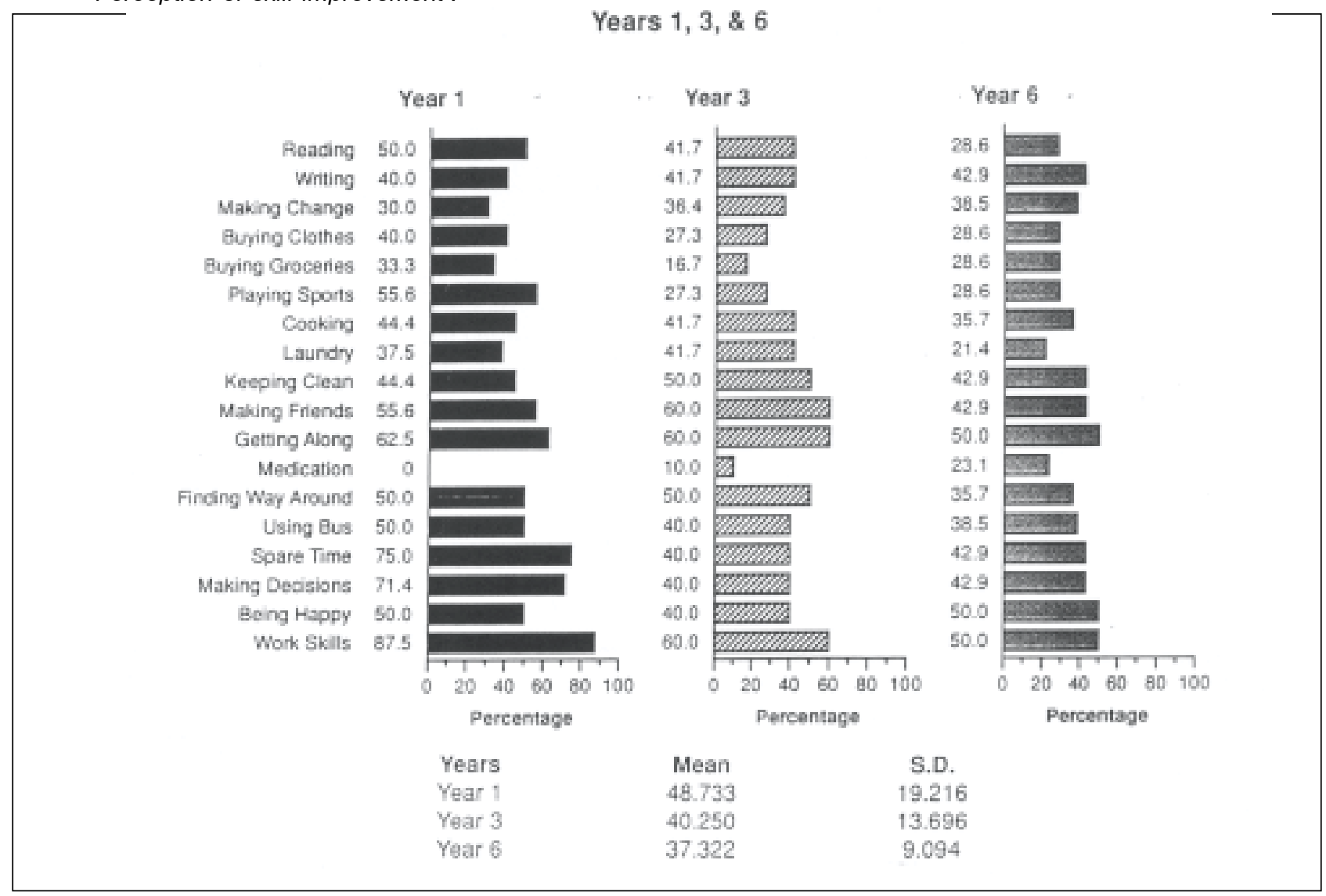




\section{References}

Brown,R.I., Bayer,M.B. and MacFarlane,C. (1989) Rehabilitation programmes: Performance and quality of life of adults with developmental handicaps. Toronto: Lugus.

Brown,R.I., Bayer,M.B. and Brown,P.M. (1993) Empowerment and developmental handicaps: Choices and quality of life. Toronto: Captus University Publications, and London: Chapman and Hall.

Brown,R.I. (1993) Social life, dating and marriage. In Proceedings of the National Down Syndrome Society. Orlando (in press)

Brown,R.I. and Bayer,M.B. (1993) Rehabilitation questionnaire: A Personal guide to the individual's quality of life. Ontario: Captus University Publications.

Gibson,D. (1978) Down's Syndrome. Cambridge: Cambridge University Press.

Lawrence,P., Brown,R.I., Mills,J. and Estay,I. (1993)Adults with Down syndrome; Together we can do it. Toronto: Captus Press, and Calgary: Canadian Down Syndrome Society.
Marlett,N.J. (1976) Adaptive Functioning Index. Calgary: Vocational and Rehabilitation Research Institute.

Pueschel,S.M. (1988) The young person with Down syndrome: Transition from adolescence to adulthood. Baltimore: Paul Brookes.

Selikowitz,M. (1992) Down syndrome: The facts. In Roy I. Brown Building our Future, The 1992 National Conference of the Canadian Down Syndrome Society, Calgary.

Address for correspondence (from March 1994):

Professor Roy I Brown,

Foundation Chair in Special Education, Department of Special Education,

The Flinders University of South Australia, GPO Box 2100, Adelaide 5001, Australia.

\section{International Conference on Language and Cognitive Development in Down's Syndrome}

\section{The University of Portsmouth, U.K.}

\section{2 - 25 September 1994}

\section{Keynote speakers:}

Professor Jon Miller

University of Wisconsin, Madison, U.S.A.

Early language development of chiildren with Down's syndrome, $0-5$ years

\section{Dr Anne Fowler}

Bryn Mawr College \& Haskins Laboratories, New Haven Connecticut, U.S.A.

Reading, phonemic awareness and phonological memory in Down's syndrome

\section{Dr Robin Chapman}

University of Wisconsin, Madison, U.S.A.

Language development in children and adolescents with Down's syndrome, 5-20 years

\section{Professor Jean Rondal}

University of Liege, Belgium

Language in adults with Down's syndrome

\section{Dr Sue Gathercole}

University of Lancaster, U.K.

The links between working memory and language development in Down's syndrome

\section{Dr John Clibbens}

University of Plymouth, U.K.

The effects of teaching sign on language development of children with Down's syndrome

\section{Dr David Messer}

University of Hertfordshire, U.K.

The links between early cognitive development and language in children with Down's syndrome

\section{Sue Buckley}

University of Portsmouth, U.K.

The theoretical and practical significance of teaching literacy skills to children with Down's syndrome

The aim of the conference is to bring together all the leading international researchers to discuss the current state of our knowledge and identify areas for future research. To this end it will be a large seminar (200-250) for professionals (mainly psychologists, speech and language therapists) and parents. Poster presentations by participants will be welcomed. Deadline for poster submissions: 31 May 1994.

For further details and booking forms please contact the Sarah Duffen Centre: Belmont Street, Southsea, PO5 1NA, U.K. Tel: 0705 82426,1 Fax: 0705 824265, International tel: +44 705 824261. E Mail: Buckleys @ UK.AC.PORTSMOUTH.CSOVAX. 